\title{
Electrochemical Noise Analysis for Different Green Corrosion Inhibitors for Copper Exposed to Chloride Media
}

\author{
A.M. Nagiub * \\ Al-Azhar University, Faculty of Science, Chemistry Department, Assuit, Egypt
}

Received April 22, 2016; accepted December 23, 2016

\begin{abstract}
Four different herbal compounds, Anise (Pimpinella Anisum), Caraway (CARUM Carvi), Cumin (Cuminum Cyminum) and Hibiscus (Hibiscus Sabdarriffa) have been tested as green corrosion inhibitors for copper exposed to $0.5 \mathrm{M} \mathrm{NaCl}$. The corrosion inhibition has been studied using electrochemical noise analysis (EN) and electrochemical impedance spectroscopy (EIS). The comparative analysis of the results obtained showed that EN is an effective tool for screening of new corrosion inhibitors. Analysis of noise data demonstrated the need of removal of the trends in the potential and current fluctuations during the measurement periods. The results gathered showed very good inhibition efficiency. Generally, EN showed a good correlation with EIS in this study.
\end{abstract}

Keywords: Copper; EN; EIS; Herbal compounds.

\section{Introduction}

Environmental restriction of application of inhibitors has reoriented researchers to prefer natural compounds, called green corrosion inhibitors [1-4]. Natural plants, added in form of extracts, oil or pure compounds, may play a major role in keeping the environment healthier, safe and under pollution control. Recently, different herbal compounds have been widely used as corrosion inhibitors $[1,2]$. Among various natural products very few data have been reported for the use of Anise, Caraway, Cumin and Hibiscus as corrosion inhibitors [1].

A great interest concerning the use of electrochemical noise in corrosion studies has attracted the attentions of many corrosion scientists, due to its simplicity and low cost; however, the technique is still under investigation [5-8]. First studies on EN were carried out using only one working electrode, which, consequently, did not allow the measurement of corrosion rate. Eden et al. introduced the use of a cell with two identical working electrodes connected with a zero resistance ammeter (ZRA), so that it was possible to simultaneously collect both the current and potential fluctuation [9]. The validity of statistical parameters such as

\footnotetext{
* Corresponding author. E-mail address: adham.nagiub@gmail.com
} 
localization index (LI), skewness and kurtosis, and frequency parameters such as power spectral density (PSD) slopes obtained from analyzing the EN in the time and frequency domains have been discussed by Mansfeld et al. [10,11]. LI was defined as the ratio of the standard deviation and the root mean square of current fluctuation in EN measurements; it can have values between 0 and 1 . It was assumed that LI could be used to differentiate between distinct kinds of corrosion mechanisms [12]. A theoretical and experimental analysis of the effects of trend in potential and current noise fluctuations observed during measurement of EN data has been carried out by Mansfeld et al. [10]. The aim of the present study was to investigate the validity of electrochemical noise technique in assessing the inhibition efficiency of different herbal compounds as green inhibitors for copper corrosion in a $\mathrm{NaCl}$ solution.

\section{Experimental procedure}

Four different herbal compounds, anise (pimpinella anisum), caraway (carum carvi), cumin (cuminum cyminum) and hibiscus (hibiscus sabdarriffa) were used in this study. A $10 \mathrm{gm}$ sample of each of the dried herbal samples was refluxed in $100 \mathrm{~mL}$ double distilled water for $1 \mathrm{hr}$. The refluxed solution was filtered to remove any contaminations. The concentration of the stock solution was determined by evaporating $10 \mathrm{~mL}$ of the filtrate and weighting the residue [13]. Symbols K, C, J and W will refer to hibiscus, cumin, anise and caraway, respectively. For each experiment, electrochemical measurements were carried out in a two identical electrodes configuration cell (2E), with a saturated calomel reference electrode (SCE). The tested electrode was pure copper sheet $(99.9 \%)$ with an exposed area of $1 \mathrm{~cm}^{2}$. All corrosion measurements were performed in a $0.5 \mathrm{M} \mathrm{NaCl}$ solution. Prior to corrosion testing, copper samples were subjected to mechanical polishing up to the grit size of 1200 silicon carbide paper, then cleaned in acetone. All corrosion experiments were carried out for a duration varying between 6 hours to 96 hours, at $25^{\circ} \mathrm{C}$.

Two different electrochemical techniques were used to evaluate the corrosion behavior of copper, electrochemical impedance spectroscopy (EIS) and electrochemical noise analysis (EN). EN was performed in a set-up with an electrochemical cell consisting of two identical copper electrodes with an exposed area of $1.0 \mathrm{~cm}^{2}$ for each electrode, and an SCE as a reference electrode within a Faraday cage. An AutoCAD DSP device (ACM Instruments) was used to simultaneously collect potential and current fluctuations. Potential and current fluctuations were obtained with a sampling rate of 2-point $\mathrm{s}^{-1}$ during a time period of 1024 seconds, which fixed the frequency range $(\Delta f)$ in a region between $1 \mathrm{~Hz}$ and about $1 \mathrm{mHz}$. The instrument noise was tested and shown to have no influence on the noise measurements. A polynomial trend removal method was performed to remove the direct current (DC) trend contained in the noise data. The analysis of EN data in time domain was developed using Mathcad PLUS 6 software. EIS was performed with the AutoCAD DSP device (ACM Instruments). A sinusoidal perturbation of $10 \mathrm{mV}$ rms was applied at the cell over the frequency range of $30 \mathrm{kHz}-0.005 \mathrm{~Hz}$. EIS was immediately conducted after EN, using the same cell. 


\section{Results and discussion}

The time dependence of the open circuit potential $\left(E_{\text {corr }}\right)$ for copper, when exposed to $0.5 \mathrm{M} \mathrm{NaCl}$ with and without different kinds of $0.1 \mathrm{~g} / \mathrm{L}$ herbal concentration, is shown in Fig. 1. It is clear that the presence of herbal compounds causes a shift in the negative direction of $\mathrm{E}_{\text {corr }}$, except for $\mathrm{K}$. Maximum negative shift was achieved for the solution containing $\mathrm{W}$. The negative shift was increased according to the following sequence: $\mathrm{W}>\mathrm{C}>\mathrm{J}$. After about 48 hours immersion, $\mathrm{E}_{\text {corr }}$ did not change much with the exposure time for $\mathrm{K}, \mathrm{C}$ and $\mathrm{W}$, while $\mathrm{E}_{\mathrm{corr}}$, in the absence of herbal compounds, gradually decreased as a function of time (negative shift), from about -0.210 to -0.260 Volt (SCE).

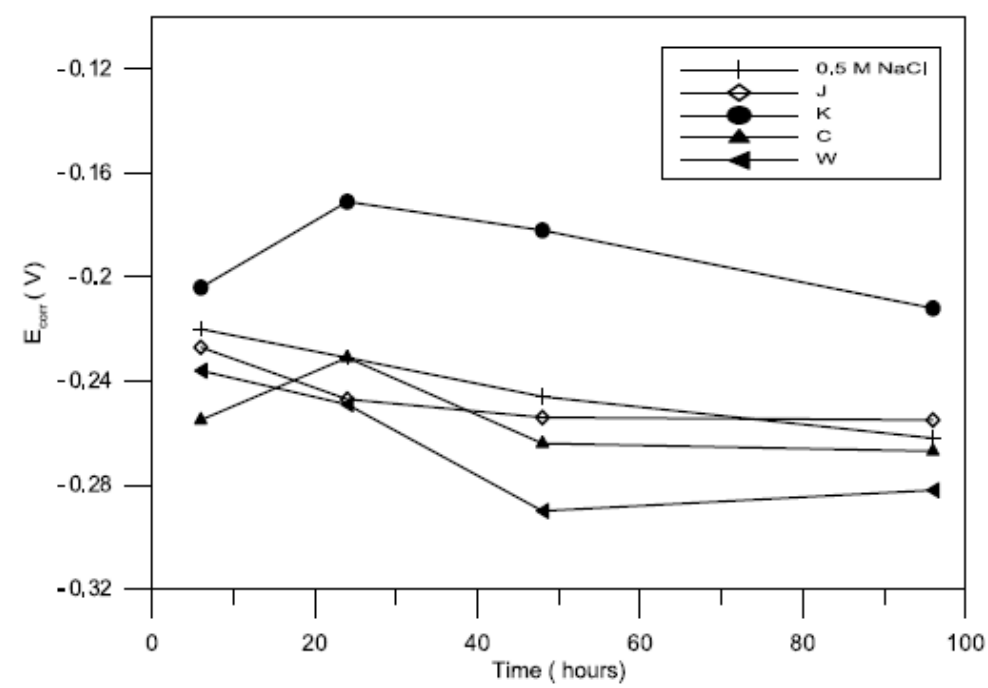

Figure 1. Time dependence of $\mathrm{E}_{\text {corr }}$ for copper exposed to $0.5 \mathrm{M} \mathrm{NaCl}$ with and without different herbal compounds ( $\mathrm{C}$ - cumin, $\mathrm{J}$ - anise, $\mathrm{K}$ - hibiscus, $\mathrm{W}$ - caraway).

Fig. 2 shows Bode plots for copper exposed to $0.5 \mathrm{M} \mathrm{NaCl}$, with and without different herbal compounds, after 6 hours. There are clear differences between the spectra obtained in a solution containing herbal compounds and in its absence. The appearance of second phase angle not exceeding $45^{\circ}$ at the lowest frequency region is considered to be an indicative of diffusion process [11]. For copper exposed to $0.5 \mathrm{M} \mathrm{NaCl}$ a diffusion process was observed with a maximum phase angle of about $-50^{\circ}$ and $\mathrm{Rp}$ value of about $3 \times 10^{2} \mathrm{Ohm}$ (Fig. 2). It is clear that the impedance was much higher for copper exposed to $\mathrm{NaCl}$ in the presence of $\mathrm{W}, \mathrm{C}$ and $\mathrm{J}$, than in their absence. No significant change in the impedance was observed in the solution containing $\mathrm{K}$. A similar effect was observed for copper exposed to $\mathrm{NaCl}$, with and without herbal compounds, after 4 days (Fig. 3). The increased impedance followed the following sequence: $\mathrm{C}>\mathrm{J}$ $>\mathrm{W}>\mathrm{K}$.

The impedance response of the copper samples is approximated by an appropriate equivalent circuit (EC). Impedance spectra for copper were analyzed using the open boundary finite length diffusion model (OFLD) [11]. 


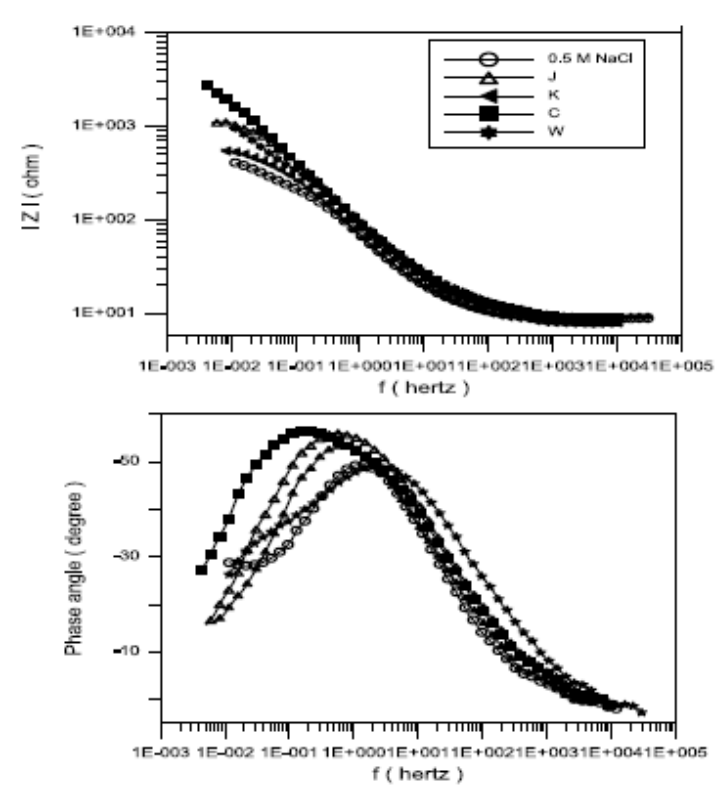

Figure 2. Bode plots for copper exposed to $\mathrm{NaCl}$, with and without different herbal compounds, after 6 hours.
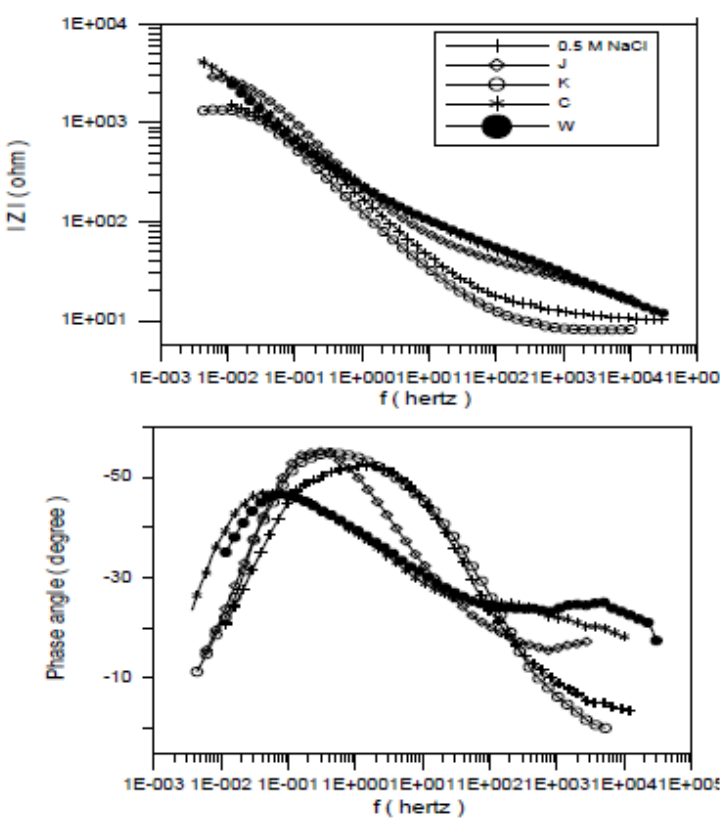

Figure 3. Bode plots for copper exposed to $\mathrm{NaCl}$, with and without different herbal compounds, after 4 days.

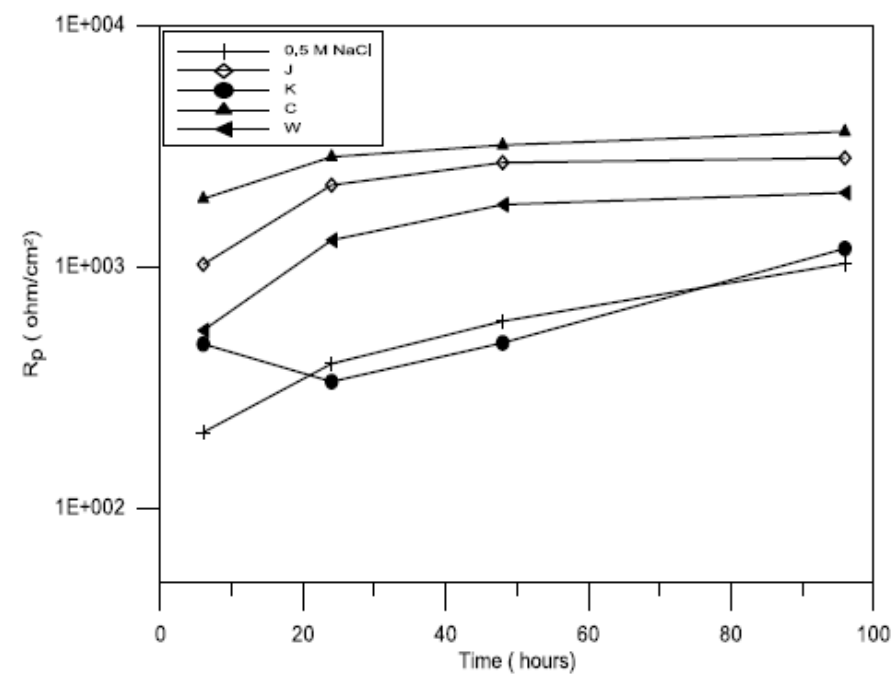

Figure 4. Time dependence of $\mathrm{R}_{\mathrm{p}}$ for copper exposed to $0.5 \mathrm{M} \mathrm{NaCl}$, with and without different herbal compounds.

Fig. 4 shows the time dependence of $R_{p}$ in the presence and absence of different herbal compounds. The $\mathrm{R}_{\mathrm{P}}$ values obtained for all of the tested herbal compounds, except K, were much higher than those obtained for copper exposed to $\mathrm{NaCl}$ only.

The increased values of $R_{p}$ will reflect the inhibitive effect of the corrosion of copper due to the presence of such compounds. It is also clear that the corrosion inhibition reached its maximum values for the solution containing $C$. $R_{p}$ values were slightly increased for all the tested solutions, which indicates improvement of corrosion inhibition with time. The increased $R_{p}$ values followed the following sequence: $\mathrm{C}>\mathrm{J}>\mathrm{W}>\mathrm{K}$. 

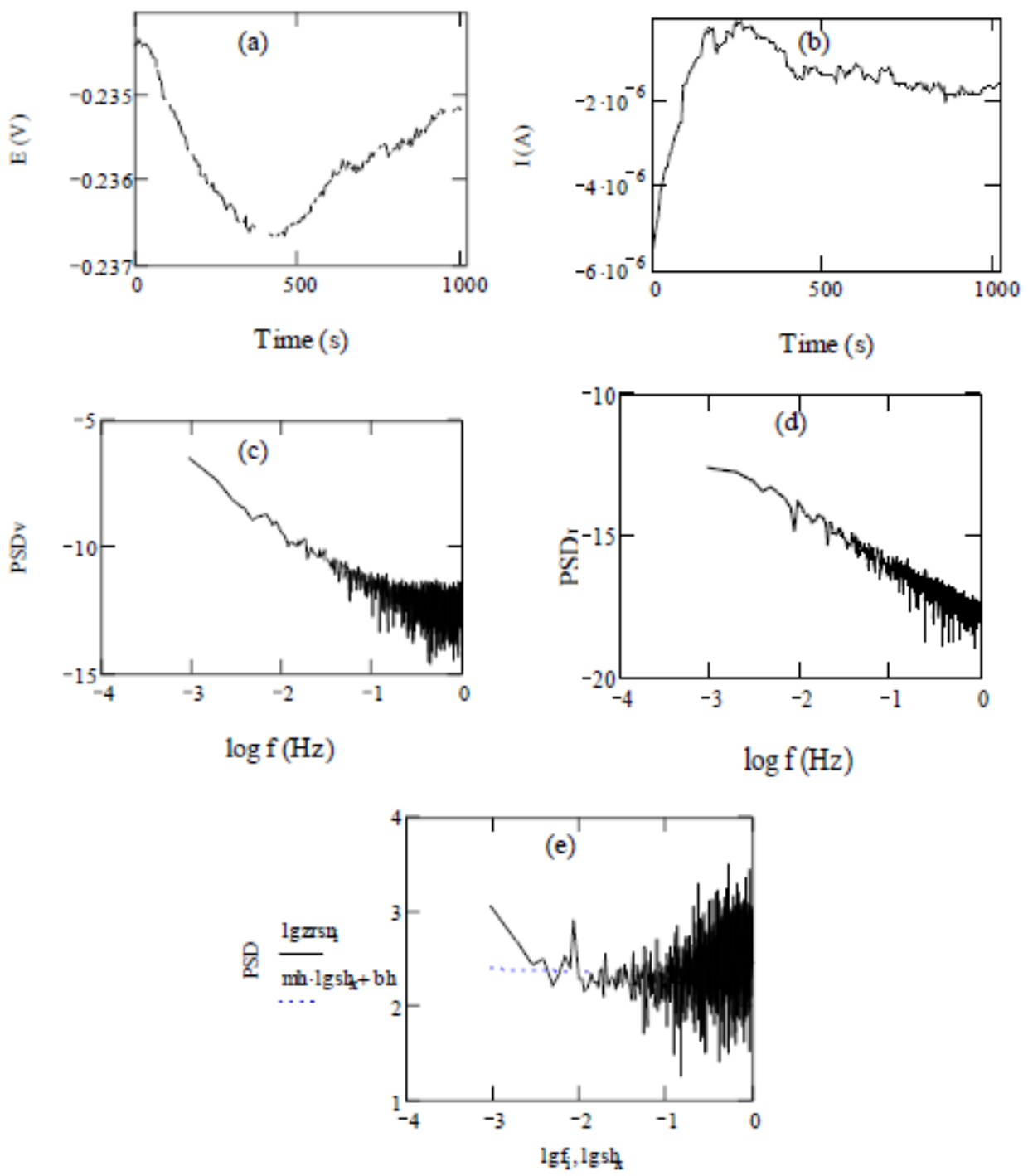

$\log \mathrm{f}(\mathrm{Hz})$

Figure 5. EN data in the time and frequency domains for copper exposed to $\mathrm{NaCl}$ containing W, for 6 hours.

The potential and current noise were simultaneously recorded as described in the experimental section, and the data were analyzed in both time and frequency domains. Fig. 5 shows the experimental EN data for copper exposed to $0.5 \mathrm{M}$ $\mathrm{NaCl}$ containing W, after 6 hours in the time domain ( Fig. 5 (a), (b)) and the frequency domain (Fig. 5 (c)-(e)), while Fig. 6 represents the corresponding EN data after trend removal. As discussed before, the presence of trend can mask the shape and current fluctuations, and may affect the slopes of PSD plots [10,11]. The noise resistance, $R_{n}$, was determined in the time domain, as the ratio of the standard deviation of potential noise, $\sigma \mathrm{V}$, to that of current noise, $\sigma \mathrm{I},\left(\mathrm{R}_{\mathrm{n}}=\right.$ $\sigma \mathrm{V} / \sigma \mathrm{I})$. This parameter can be used to calculate the corrosion rate, assuming that $R_{n}$ is equivalent to polarization resistance $R_{p}$ [15]. Fig. 7 shows the time dependence of $\mathrm{R}_{\mathrm{n}}$ for copper exposed to $\mathrm{NaCl}$, with and without different herbal compounds. The high $\mathrm{R}_{\mathrm{n}}$ values obtained for $\mathrm{W}, \mathrm{C}$ and $\mathrm{J}$ coincided with the corresponding $R_{p}$ values obtained from the impedance study. $R_{n}$ values for $W, K$ 
and $\mathrm{C}$ slightly increased with time, which indicates improvement of corrosion inhibition. These results also coincided with $R_{p}$ values obtained before. After 4 days of exposure, $R_{n}$ values reached their maximum value (Fig. 7). Accordingly, the obtained results suggested that these inhibitors could be very effective for the studied period.
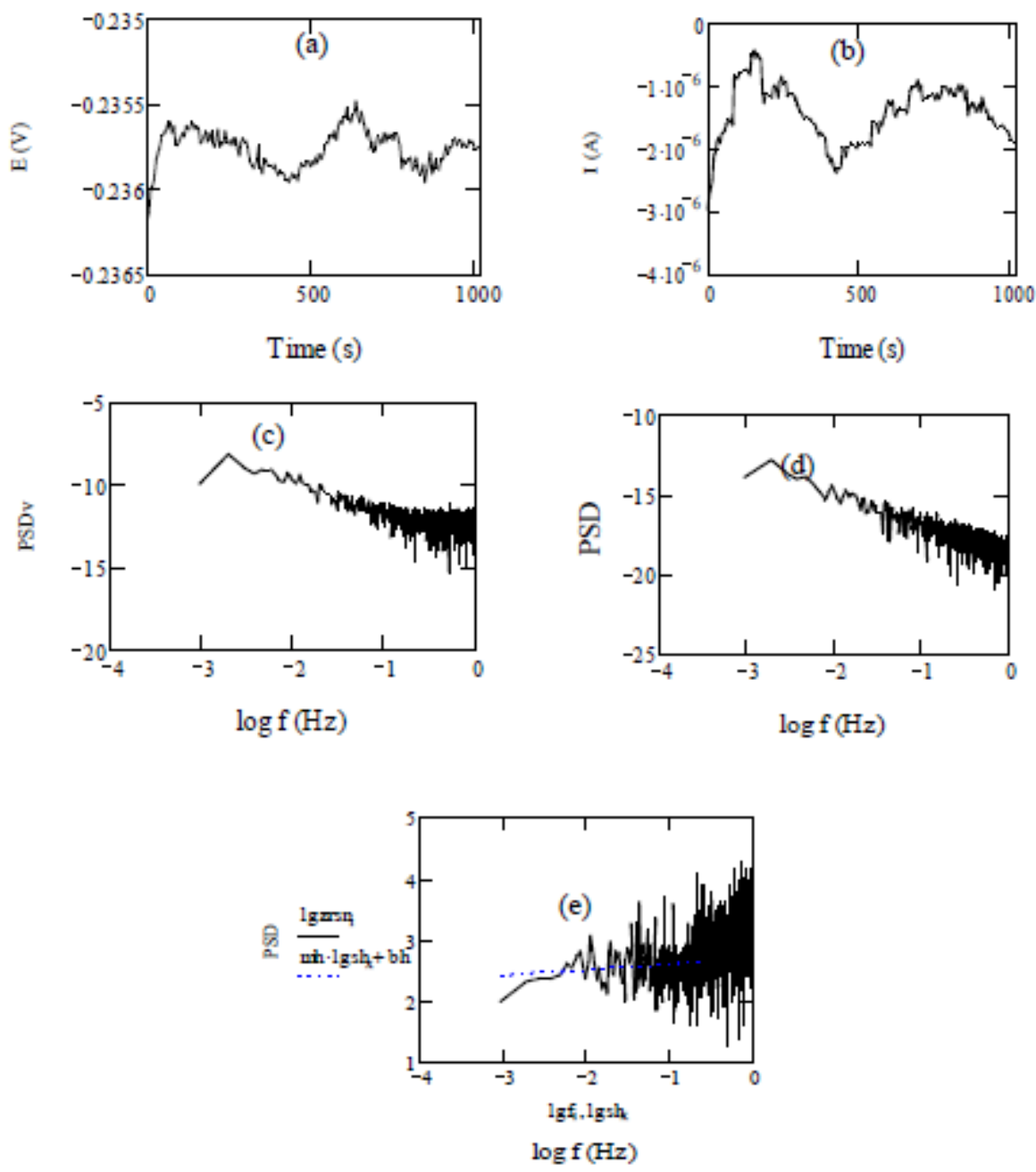

Figure 6. EN data in the time and frequency domains for copper exposed to $\mathrm{NaCl}$ containing $\mathrm{W}$, for 6 hours after trend removal.

The localization index (LI) is defined as the ratio of the standard deviation of $\sigma_{\mathrm{i}}$ and the root mean square of the current $\mathrm{I}_{\text {rms. }}$ LI has values between 0 and 1 . It has often been assumed that LI values can be used to differentiate between different types of corrosion; for example, LI close to 1 corresponds to localized corrosion, while LI close to zero suggests general corrosion [7]. LI data obtained for copper exposed to $0.5 \mathrm{M} \mathrm{NaCl}$, with and without different herbal compounds, are shown in Fig. 8. LI values were close to zero for all the tested solutions. The values obtained in this study indicate that LI cannot be used to differentiate between types of corrosion, which is in agreement with our previous results. It was concluded that LI could not be used to determine the corrosion mechanisms $[10,11]$. 

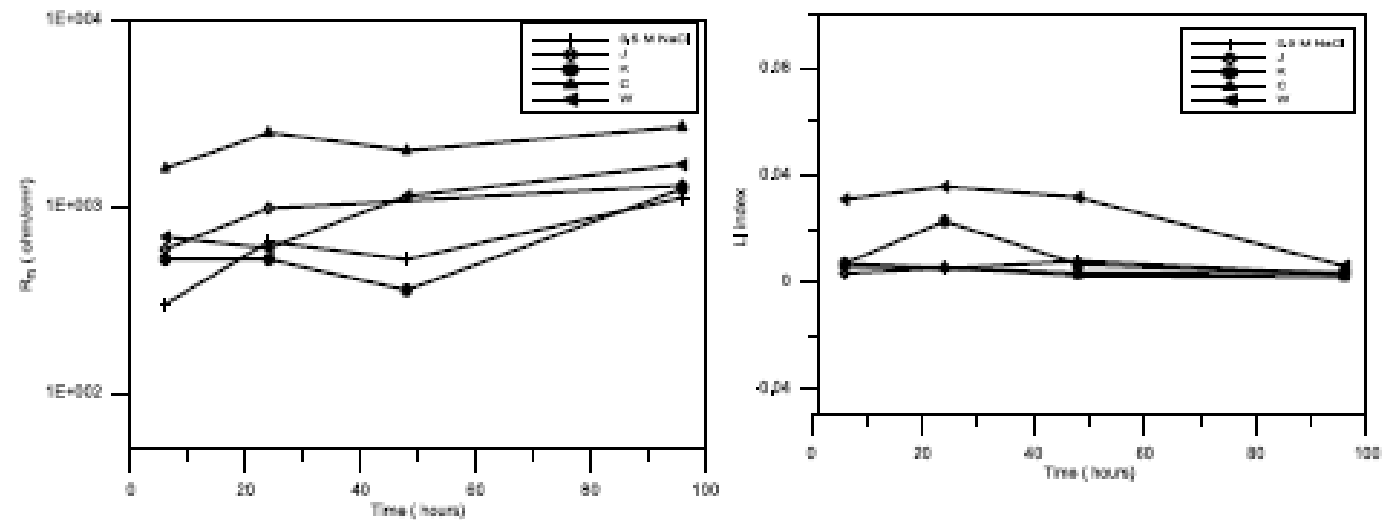

Figure 7. Time dependence of $\mathrm{R}_{\mathrm{n}}$ for copper exposed to $0.5 \mathrm{M} \mathrm{NaCl}$, with and without different herbal compounds.

Figure 8. Time dependence of LI for copper exposed to $0.5 \mathrm{M} \mathrm{NaCl}$, with and without different herbal compounds.

Kurtosis is a measure of the shape of EN data. The kurtosis will be 3 for normal distribution; for values higher than 3 the normal distribution will be sharply peaked; and for values lower than 3 it will be more flat [16]. Skewness describes the asymmetry of the probability distribution of EN data. For a symmetric distribution the skewness will be zero. Positive values indicate that the data are skewed to the right from the normal distribution, which means that the distribution is concentrated in its leftmost part with a long thin tail to the right, while negative values mean that the distribution is skewed to the left [16]. Eskew and $\mathrm{I}_{\text {skew }}$ are the skewness of the potential and current fluctuations, respectively. $E_{\text {kurt }}$ and $I_{k u r t}$ are the kurtosis of the potential and current fluctuations, respectively.

Fig. 9 shows the time dependence of skewness and kurtosis for both current and potential fluctuations for copper exposed to $0.5 \mathrm{M} \mathrm{NaCl}$, with and without different herbal compounds. Skewness and kurtosis were independent of time with similar values in the presence and absence of herbal compounds, indicating that skewness and kurtosis are only measures of the distribution of current and potential fluctuations, and that the presence of such inhibitor did not change this distribution. Accordingly, skewness and kurtosis did not provide any mechanistic information.

In order to compare noise data, Fast Fourier Transform (FFT) was used to convert the noise data from time domain to frequency domain. The spectral noise plot $R_{\text {sn }}(f)$ is defined as $[17,18]$ :

$$
R_{s n}(\mathrm{f})=\left|\frac{V_{F F T}(f)}{I_{F F T}(f)}\right|=\left(\frac{V_{P S D}(f)}{I_{P S D}(f)}\right)^{1 / 2}
$$

where, $V_{F F T}$ and $I_{F F T}$ will refer to the Fast Fourier Transformer functions of the potential and current noise, respectively, and $V_{P S D}$ and I PSD are the corresponding PSD plots.

Fig. 10 shows a comparison between the spectral noise plots and impedance plot for copper exposed to a $\mathrm{NaCl}$ solution containing $\mathrm{K}$ before (a) and after (b) trend 
removal. It is obvious that no agreement between the noise and impedance plots was observed before trend removal (Fig. 10 (a)); however, after trend removal, a very good agreement was observed (Fig. 10 (b)). Analysis of noise data demonstrated the need for removal of the drifts in the potential and current fluctuations during the measurement periods.
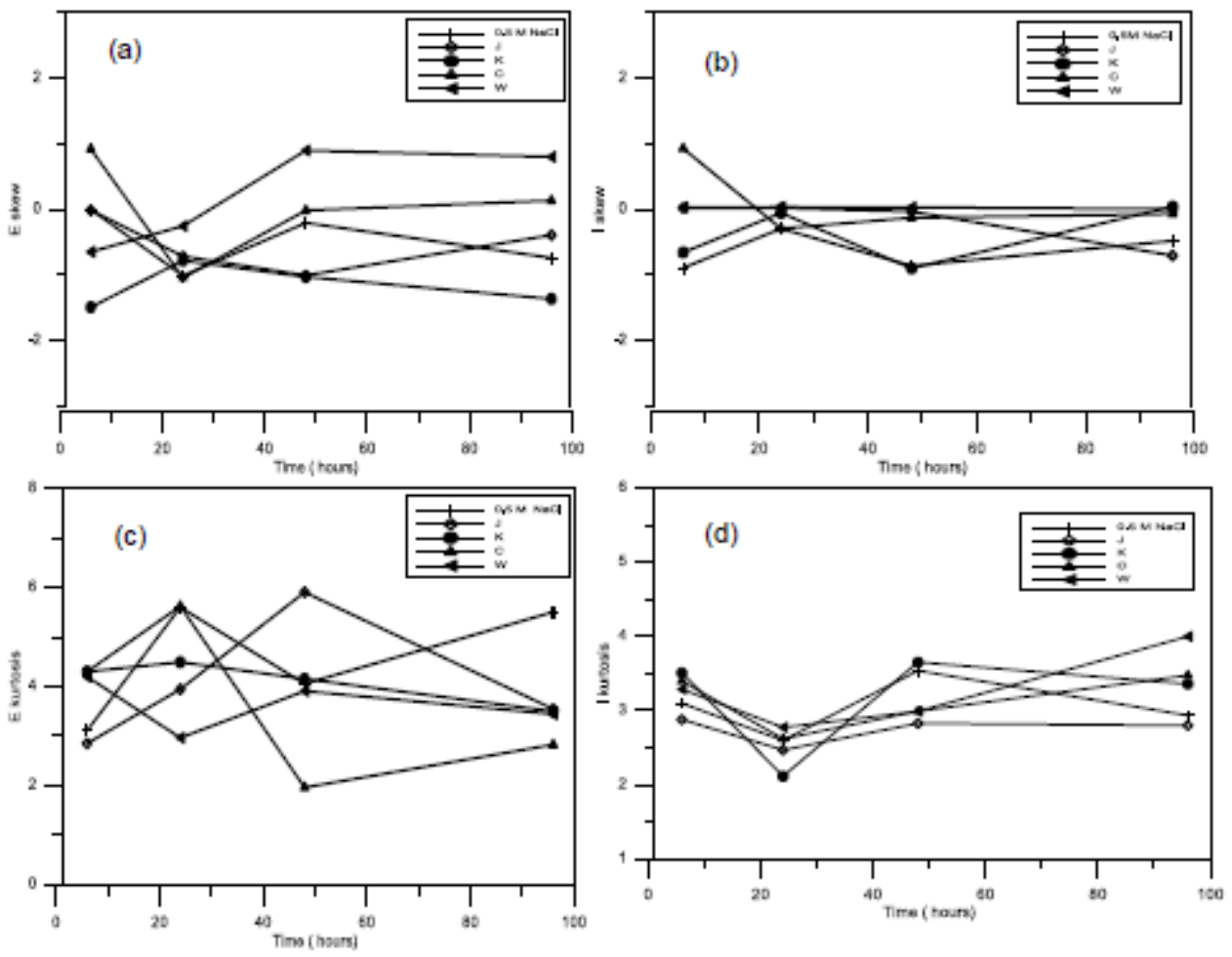

Figure 9. Time dependence of $E_{\text {skew }}(a), I_{\text {skew }}(b), E_{\text {kurt }}(c)$, and $I_{k u r t}(d)$ for copper exposed to $0.5 \mathrm{M} \mathrm{NaCl}$, with and without different herbal compounds.
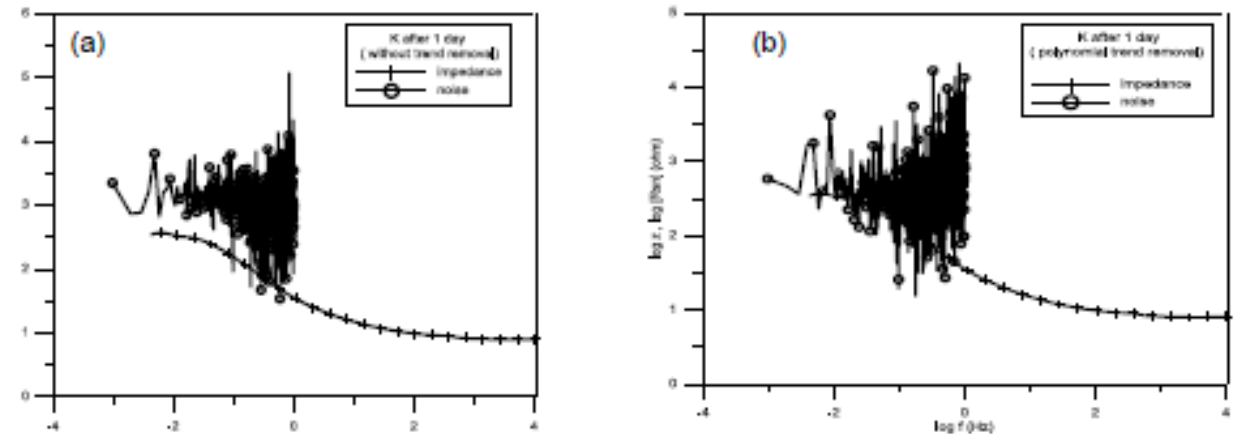

Figure 10. Impedance and spectral noise plots comparison for copper exposed to $0.5 \mathrm{M}$ $\mathrm{NaCl}$ with $\mathrm{K}$ for 1 day before (a) and after (b) trend removal.

\section{Conclusions}

The experimental results show that the tested herbal compounds are good corrosion inhibitors of pure copper exposed to a solution of $0.5 \mathrm{M} \mathrm{NaCl}$.

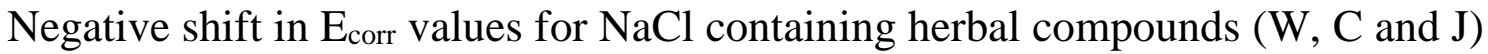
may indicate that these compounds worked as cathodic inhibitors. EIS showed that the corrosion mechanism is controlled by diffusion process. $\mathrm{R}_{\mathrm{p}}$ values were 
increased to a large extent in the presence of herbal compounds. The increased impedance followed the sequence $C>J>W>K$. The obtained $R_{n}$ values were nearly similar to $R_{p}$ values. It can be concluded that $R_{n}$ successfully followed the corrosion behavior of copper exposed to $\mathrm{NaCl}$ in the presence and absence of herbal compounds such as EIS. Analysis of noise data demonstrated the need for removal of the trends in the potential and current fluctuations during the measurement periods. Skewness and kurtosis data did not provide any mechanistic information and were only indicative of normal distribution of the noise data. Analysis of EN data in the frequency domain was used to compare the impedance data to EN data. It was concluded that EN could detect the corrosion rate for copper exposed to chloride media, but was not found to provide information about the corrosion mechanisms. The comparative analysis of the results obtained showed that $\mathrm{EN}$ is an effective tool for screening of new corrosion inhibitors. Further studies are required to clarify why one herb works better than the other, by going into the structural part of the inhibitor molecule and its inhibition mechanism.

\section{Acknowledgments}

The author would like to acknowledge the financial support of Chemistry Department, Faculty of Science, Al-Azhar University (Assuit branch) in this study.

\section{References}

1. Kamis E, AlAndis N. Herbs as New Type of Green Inhibitors for Acidic Corrosion of Steel. Mater Corros. 2002;33:550-554.

2. Ouachikh O, Bouyanzer A, Bouklah M, et al. Application of |Essential Oil of Artemisia Herba Alba as Green Corrosion Inhibitor for Steel in $0.5 \mathrm{M}$ $\mathrm{H}_{2} \mathrm{SO}_{4}$. Surf Rev Letters. 2009;16:49-54.

3. Cui R, Gu N, Li C. Polyaspartic acid as a green corrosion inhibitor for carbon steel. Mater Corros. 2001;62: 362-369.

4. Ghareba S, Omanovic S. Interaction of 12-aminododecanoic acid with a carbon steel surface: towards the development of 'green' corrosion inhibitors. Corros Sci. 2010;52:2104-2113.

5. Mansfeld F, Sun Z, Speckert E, et al. Electrochemical Noise Analysis (ENA) For Active and Passive Systems. Corrosion/2000. Houston, TX: NACE International; 2000. paper 418.

6. Aballe A, Bautista A, Bertocci U, et al. The Measurement of Noise Resistance for Corrosion Application. Corrosion/2000. Houston, TX: NACE International; 2000. paper 424.

7. Eden DA, Hladky K, John DG, et al. Electrochemical Noise-Simultaneous Monitoring of Potential and Current Noise Signals from Corroding Electrodes. Corrosion/86. Houston, TX: NACE International; 1986. paper 274. 
8. Nagiub A, Mansfeld F. Microbiologically influenced corrosion inhibition (MICI) due to bacterial contamination. Mater Corros. 2001;52:817-826.

9. Eden DA, Hladky K, John DG, et al. Electrochemical Noise-Simultaneous Monitoring of Potential and Current Noise Signals from Corroding Electrodes. Corrosion/86. Houston, Texas: NACE; 1986. Paper 274.

10. Mansfeld F, Sun Z, Hsu CH, et al. Concerning trend removal in electrochemical noise measurements. Corros Sci. 2001;43:341-352.

11. Nagiub A, Mansfeld F. Evaluation of corrosion inhibition of brass in chloride media using EIS and ENA. Corros Sci. 2001;43:2147-2171.

12. Eden DA. Electrochemical Noise-The First two Octaves. Corrosion/98. Houston, TX: NACE; 1998. Paper 386.

13. Abdel-Gaber AM, Abd-El-Nabey BA, Sidahmed IM, et al. Inhibitive action of some plant extracts on the corrosion of steel in acidic media. Corros Sci. 2006;48:2765-2779.

14. Rammelt U, Reinhard G. On the applicability of a constant phase element (CPE) to the estimation of roughness of solid metal electrode. Electrochim Acta. 1990;35:1045-1049.

15. Mansfeld F, Xiao H. Evaluation of Coating Degradation with Electrochemical Impedance Spectroscopy and Electrochemical Noise Analysis. J Electrochem Soc. 1994;141: 2332-2337.

16. Wesley J. Statistical Analysis for Engineers and Scientists. McGraw-Hill; 1994.

17. Mansfeld F, Xiao H, Han LT, et al. Electrochemical impedance and noise data for polymer coated steel exposed at remote marine test site. Prog Org Coat. 1997;30: 89-100.

18. Xiao H, Han LT, Lee CC, et al. Collection of Electrochemical Impedance and Noise Data for Polymer Coated Steel from Remote Test Sites. Corrosion. 1997;53:412-422. 